\title{
Effects of Moderate Calcium Oxide Fly Ash on Expansion of Mortar Bar Due To Thai Reactive Aggregates
}

\author{
Chakkarphan Sangsuwan ${ }^{\mathrm{a}}$ and Suvimol Sujjavanich ${ }^{\mathrm{b} *}$ \\ Kasetsart University, 50 Paholyothin, Jatuchak, Bangkok 10900, Thailand \\ E-mail: Chak_sn@hotmail.coma and fengsusa@hotmail.com ${ }^{\mathrm{b}, *}$
}

\begin{abstract}
This paper reports the effect of local pozzolan on expansion of mortar bar due to local potentially reactive aggregates, greywacke. The study, based on the accelerated test method, investigated ability of moderate calcium oxide fly ash to control the length change due to chemical reaction between certain aggregates and alkalis in cement. Percentage variation of lignite fly ash from 20 to 50 yielded different benefits on expansion control. The highest percentage replacement showed the best result in reducing expansion from $0.17 \%$ to $0.03 \%$ and from $0.43 \%$ to $0.07 \%$ at 16 and 30 days after casting, respectively. The findings provided background information that would affect aggregate screening process adopted in the country and the potential mitigating method for local potential reactive aggregate.
\end{abstract}

Keywords: ASR, expansion, fly ash, greywacke.

ENGINEERING JOURNAL Volume 16 Issue 3

Received 18 November 2011

Accepted 29 February 2012

Published 1 July 2012

Online at http://www.engj.org /

DOI:10.4186/ej.2012.16.3.101

This paper is based on the poster presentation at the German-Thai Symposium on Nanoscience and Nanotechnology 2011_Green Nanotechnology of the Future, GTSNN 2011, in Nakbon Ratchasima, Thailand, 13-16 September 2011. 


\section{Introduction}

Concrete structures deteriorate in many ways. Among the latter, chemical deterioration, particularly alkalisilica reaction (ASR) has been of grave concern. ASR, reaction between some certain aggregate types and alkali in cement, results in expandable gel when moisture is available. Over a prolonged period, this causes losses of concrete integrity and durability. The difficulties in arriving at mitigation measures are compounded by the wide variations in cement and aggregates. Since Stanton reported his finding on ASR in 1940 [1], a large number of research works have been conducted in many areas, including the mitigation [2-4]. It is recognized that no single technique or material can be completely and successfully applied for all cases.

After the first evidence of ASR was reported in Thailand in 2009 in a mass foundations project [5], this phenomenon has been receiving increasing attention. Lacking in information on local materials and their behaviors in concrete has been the problem at the very start.

Many research works have focused on mitigation measures for new structures where the use of potential aggregates is unavoidable [6-7]. Several chemical admixtures and pozzolan types have been found to be variously effective[8]. Different types of pozzolan have been reported for their effective expansion control, including fly ash [9-10]. The effectiveness of fly ash, particular Type F, in reducing ASR expansion have been widely reported $[7,11]$.

The use of local fly ash in Thailand's construction industry has been significantly increasing [12-13]. This could be the results of the improvement in concrete properties, as well as environmental and economic consideration. There has been little information on fly ash and aggregates in the expansion control aspects. It is the aim of this study to rectify this.

\section{Research Objectives and Its Significance}

This paper aims to verify the effectiveness of moderate calcium oxide lignite fly ash in suppressing ASRinduced expansion of local potential reactive aggregates. The results of the study are expected to provide the information on long term expansion and cracking due to the use of local aggregates with potential for ASR.

\section{Experimental Program}

\subsection{Materials}

Local aggregates and fly ash were used throughout this study.

\subsubsection{Aggregates}

The aggregate was greywacke from a source in the east of Thailand with the production rate larger than 150 tons/hour. This aggregate was identified as a potentially reactive aggregate in the previous study [14]. Greywacke has been associated with the occurrence of ASR in several concrete structures [15], although the reactivity varied [16]. Detailed mineralogical study of the aggregate was conducted to provide information on the degrees of reactivity of the materials, as shown in Table 1 . The specific gravity and water absorption of the studied aggregates were 2.64 and $0.75 \%$ respectively. The crushed aggregates which were graded in accordance with the requirement given in ASTM C1260-01[17] and ASTM C1567-04 [18] were used throughout this study.

\subsubsection{Fly Ash}

Local fly ash from Mae Moh, the main source of Thailand was used. The chemical compositions were as follows: total amount of $\mathrm{SiO}_{2}, \mathrm{Al}_{2} \mathrm{O}_{3}$ and $\mathrm{Fe}_{2} \mathrm{O}_{3} 70.36 \%, \mathrm{CaO} 18.12 \%$, and $\mathrm{SO}_{3} 3.55 \%$. The details are shown in Table 2. The spherical shape of fly ash particles with mean diameter of 1.83 micron and the results of SEM and XRD analysis are shown in Fig. 1 [19]. Since the amount of calcium oxide in this fly ash was moderate, its effect on concrete was expected to be different. 


\subsubsection{Cement}

Commercially available Type I Portland cement was used.

Table 1. Chemical composition of Greywacke aggregate [19].

\begin{tabular}{|c|c|c|c|c|c|c|c|c|c|c|c|c|}
\hline Code & Type & Definition & 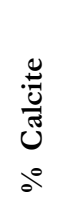 & 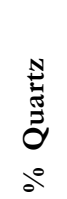 & 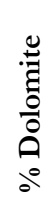 & 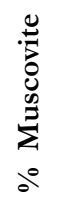 & 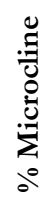 & 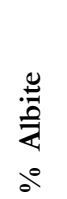 & 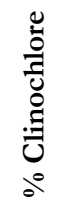 & $\begin{array}{l}\frac{0}{0} \\
\frac{0}{0} \\
\stackrel{0}{0} \\
0 \\
0^{\circ}\end{array}$ & $\begin{array}{c}\frac{\mathscr{y}}{0} \\
\partial^{\circ}\end{array}$ & $\begin{array}{l}\varepsilon \\
\vdots \\
\AA^{\circ} \\
\partial^{\circ}\end{array}$ \\
\hline TTGW & Greywacke & $\begin{array}{l}\text { East coastal } \\
\text { greywacke }\end{array}$ & 12.3 & 27.6 & - & 16.3 & 3.5 & 27.5 & 10.6 & - & 2.2 & 100 \\
\hline
\end{tabular}

Table 2. Chemical compositions of type I cement and fly ash [19].

\begin{tabular}{lcccccccccc}
\hline \multirow{2}{*}{ Oxide } & \multicolumn{10}{c}{ Composition, \% } \\
\cline { 2 - 11 } & $\mathbf{S i O}_{2}$ & $\mathbf{A l}_{2} \mathbf{O}_{3}$ & $\mathbf{F e}_{2} \mathbf{O}_{\mathbf{3}}$ & $\mathbf{C a O}$ & $\mathbf{M g O}$ & $\mathbf{N a}_{2} \mathbf{O}$ & $\mathbf{K}_{\mathbf{2}} \mathbf{O}$ & $\mathbf{M n O}_{2}$ & $\mathbf{S O}_{3}$ & $\mathbf{L O I}$ \\
\hline Cement & 18.74 & 5.22 & 3.20 & 65.30 & 0.82 & 0.08 & 0.50 & 0.06 & 2.80 & 2.75 \\
Fly ash & 36.35 & 19.86 & 14.15 & 18.12 & 2.82 & 1.33 & 2.30 & - & 3.55 & 0.55 \\
\hline
\end{tabular}
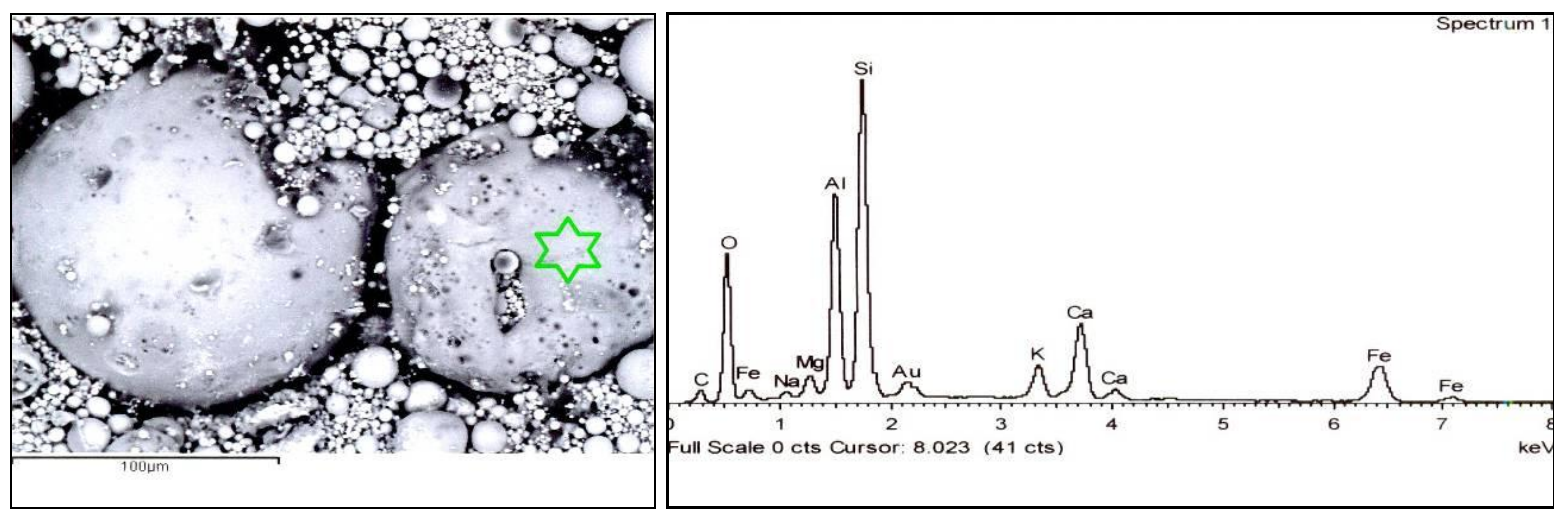

Fig. 1. Typical particle shape of fly ash (a) and XRF analysis for chemical compositions [19].

\subsection{Specimen Preparation}

Control specimens, $25 \times 25 \times 285 \mathrm{~mm}$. mortar bar, were prepared according to ASTM C 1260 using mixture with w/c of 0.47 and graded potential reactive aggregates [17]. In addition to the control, three sets of specimens were prepared, using fly ash as cement replacement at the percentage of 20, 35 and 50. Similar water to binder ratio of 0.47 and preparation procedure were used as in control samples.

\subsection{Test Methods}

\subsubsection{Length Measurement}

All specimens were demolded 24 hours after casting and stored in water at $80^{\circ} \mathrm{C}$ for 24 hours. Then, using length comparator, and following the Accelerate Mortar Bar Test (AMBT): ASTM C1260 [17] and ASTM C $1567[18]$, the reference length and the accelerated length changes were measured every two days. 
Acceleration was accomplished by immersion of the specimens in $1 \mathrm{~N} \mathrm{NaOH}$ solution at $80^{\circ} \mathrm{C}$. The measurements ended at 28 days.

\subsection{2. $\quad$ Screening Test}

After the final measurement, specimens were broken and uranyl acetate solution was sprayed on the freshly broken surface. The surface was then, rinsed off with distilled water and observed under UV light. This method was proposed by Natesaiyer and Hover [20] and has been accepted as an alternative method in ASTM C856-04 Annex [21].

\section{Results and Discussion}

\subsection{Aggregates Identification}

Mineralogy investigation, using XRD analysis, confirmed that the chosen greywacke from this source composed of calcite (12.3\%), quartz (27.6\%) and albite or feldspar (27.5\%), Muscovite (16.3\%), Microcline $(3.5 \%)$, and Clinochlore (10.6\%), were also present. Crystalline formations of the oxides are as shown in Fig. 2.

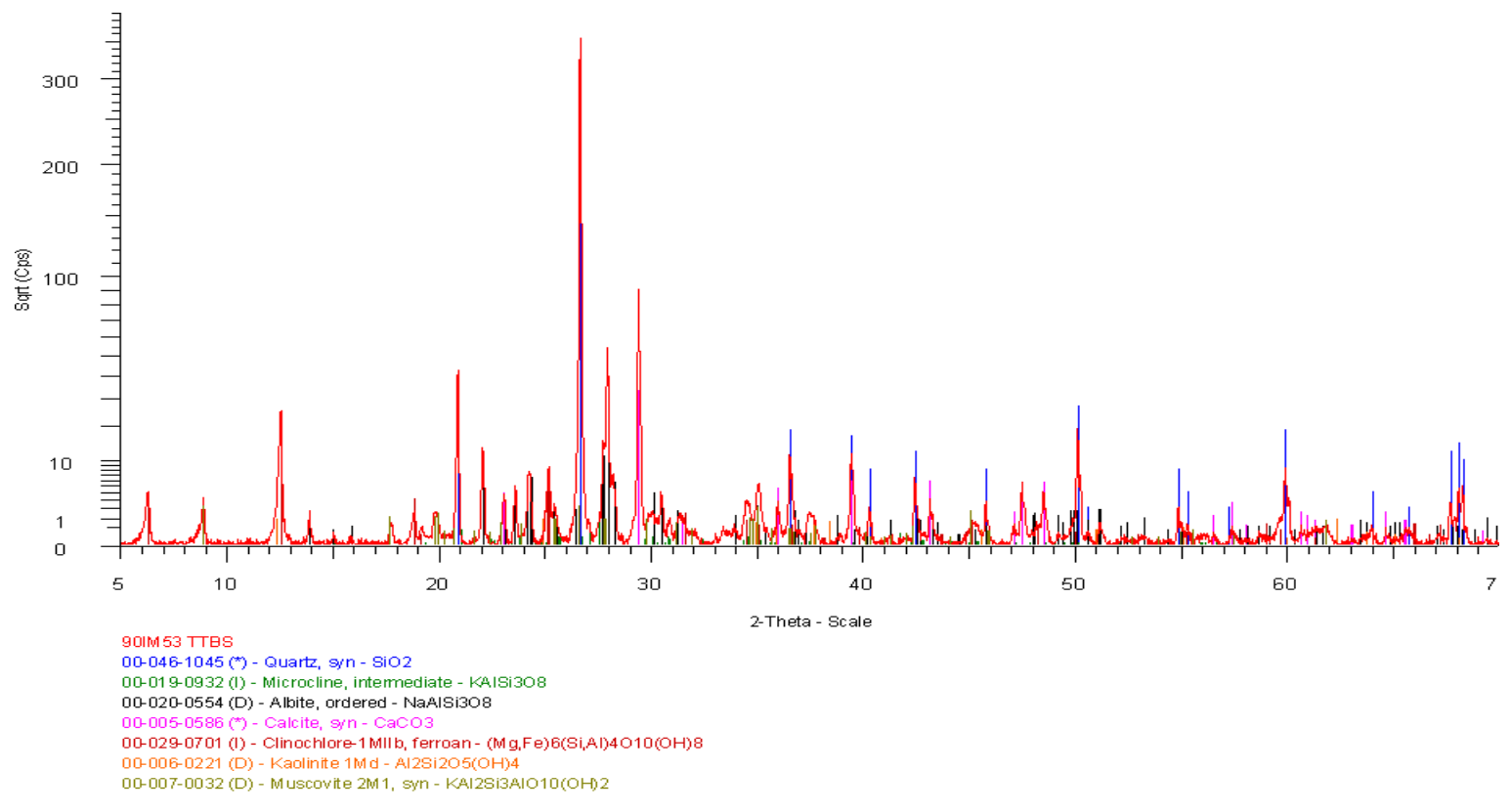

Fig. 2. XRD analysis for composition of greywacke.

\subsection{Length Changes}

The expansion test results of the control and the fly ash cement mortar bars, are shown in Fig. 3 . Expansion of the control mortar specimen $(\mathrm{M})$ was $0.167 \%$ at 16 days after casting, with continuously increasing trend. Compared to the average expansion data of $0.23 \%$ from the preliminary study of similar type and grading from the same source of aggregate and using the same testing method as shown in Fig. 4 [14], the average expansion of aggregates was slightly less. The differences could be from the natural variations in aggregate properties. However, the observed trend in this study indicated reactivity of the aggregate.

The uses of fly ash $(20 \%, 35 \%$ and $50 \%)$ in mortar samples M/PFA20, M/PFA35 and M/PFA50 yielded clear differences in effectiveness in expansion reduction. These expansions were $0.10 \%, 0.04 \%$ and $0.03 \%$ compared to that of $0.167 \%$ of the control, at 16 days after casting, with trend lines suggesting continued expansion beyond the 16 days. At 30 days, M/PFA50 yielded lowest average expansion of $0.067 \%$, compared to that of $0.434 \%$ of the control. M/PFA20 did not show an impressive expansion 
reduction, compared to the higher percentage replacement. A previous study report satisfactory expansion reduction with higher percentage of Class $\mathrm{C}$ fly ash, or lower percentage of class $\mathrm{F}$ fly ash [22], the results of this study followed the same trend.

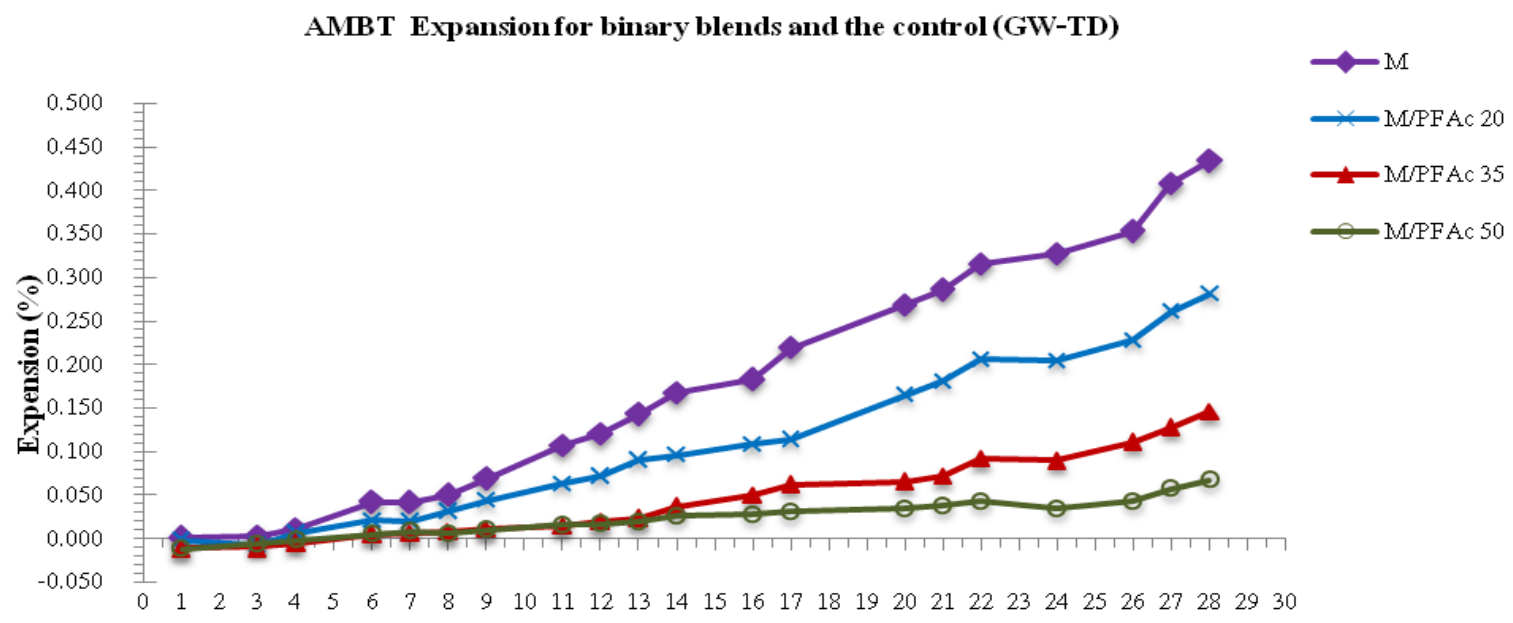

Time (days)

Fig. 3. Development of (average) expansion with time of binary blends and the control (M).

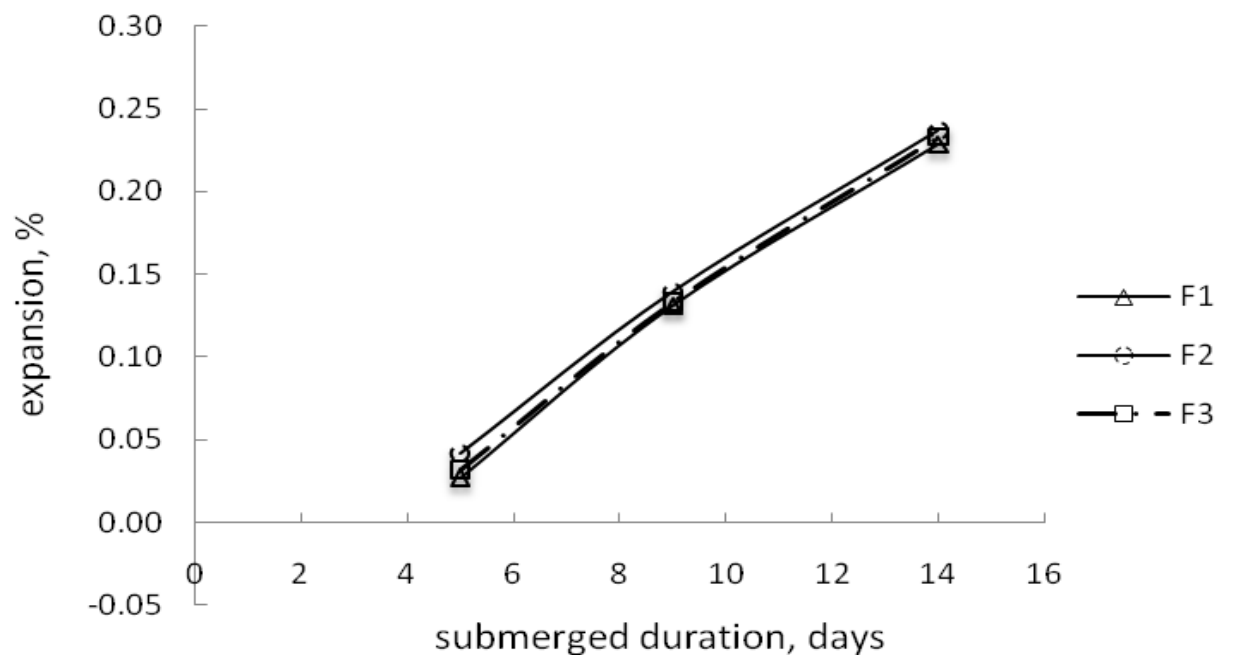

Fig. 4. Development of expansion with time of greywacke aggregates from same source, from preliminary study [14].

\subsection{Fluoresced Rim Examination in Screening Test}

From Fig. 5(a), several patches of fluoresced rims were observed in control specimen as indicated by red circles. Compared to (a), many reflected rims were also observed in the $20 \%$ replacement in (b), but less in the replacement of $35 \%$ in (c) and of 50\% in (d).Rectangles show fluoresced aggregates' rim with internal crack. Although these results are qualitative, they suggested that increasing fly ash increased the control of aggregate reactivity. The finding was supported by expansion test results. 


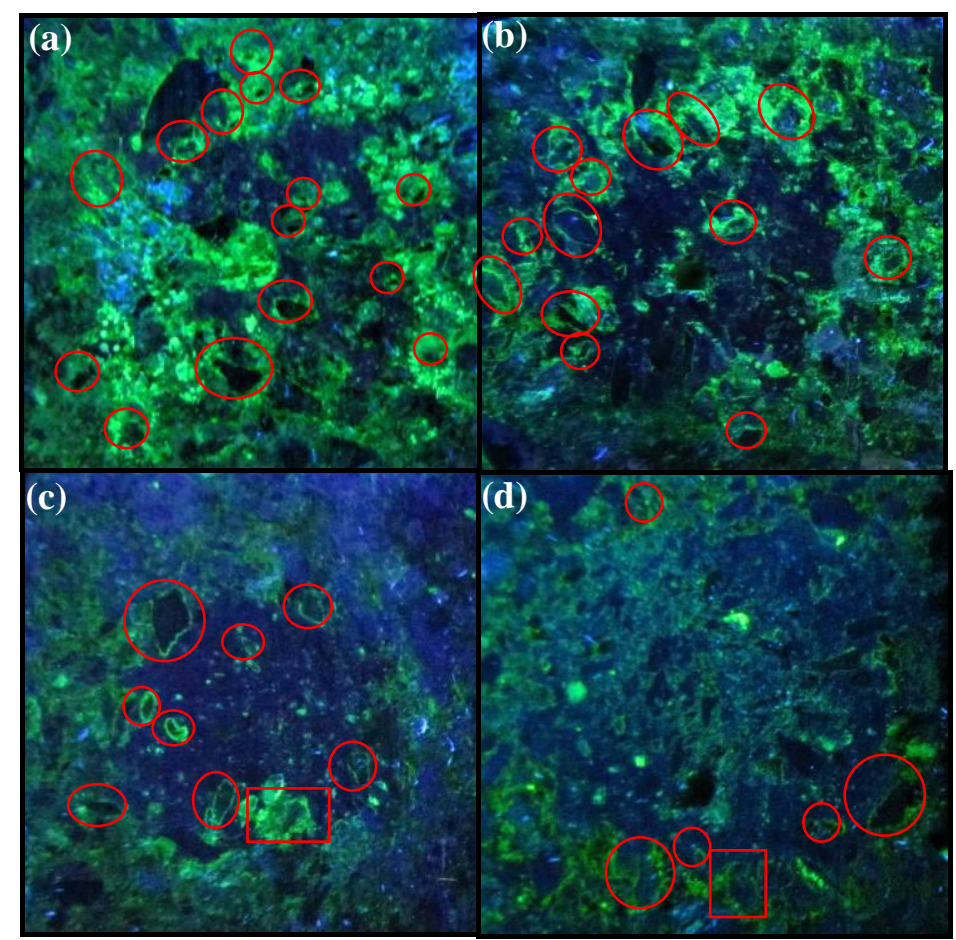

Fig. 5. Observed fluoresced rims in the cut samples with different fly ash after accelerating: (a) $0 \%$, (b) $20 \%$, (c) $35 \%$ and (d) $50 \%$.

\section{Conclusions}

For the materials used and the applied test methods in this study, the following conclusions were drawn:

(1) Moderate calcium oxide fly ash reduced ASR expansion of mortar bar.

(2) From AMBT test results, percentage of fly ash replacement of 50 provided the greatest expansion reduction, expansion from $0.17 \%$ to $0.03 \%$ and from $0.43 \%$ to $0.07 \%$ in 16 and 30 days after casting, were observed, respectively.

(3) Screening test from mortar bar samples showed the same trend as expansion test results.

(4) Using the proper percentage replacement, local fly ash showed the potential as supplement material for mitigation if the reactive aggregates must be used.

\section{Acknowledgements}

This study is funding supported by the Kasetsart University Research and Development Institute. The supported materials and their information as well as some conducted test from Siam Research and Innovation Co., LTD. and CPAC Inc. Ltd, are greatly appreciated. Also partial equipment support from Rajamagala University of Technology Phra Nakhorn is recognized.

\section{References}

[1] T. E. Stanton, "Expansion of concrete through reaction between cement and aggregate," in American Society of Civil Engineers. New York: American Society of Civil Engineers, 1940.

[2] R. N. Swamy, Ed., The Alkali-Silica Reaction in Concrete. Taylor \& Francis e-Library, 2003.

[3] D. W. Hobbs, "Alkali-silica reactions-a model for predicting expansion in Mortar," Cement and Concrete Research, vol. 33, no. 117, pp. 208-220, 1981. 
[4] G. Davies and R. E. Oberholster, "Alkali-silica reaction products and their development," Cement and Concrete Research, vol. 18, pp. 621-635, 1988.

[5] S. Sujjavanich, P. Suwanvitaya, and D. Rothstein, "Investigation of ASR in mass concrete structures: a case study," presented at ISEC-6., Zürich, 2011.

[6] D. S. Lane, "Alkali-silica reactivity in Virginia," Virginia Transportation Research Council, 1994.

[7] S. Diamond, "Effects of two Danish flyashes on alkali contents of pore solutions of cement-flyash pastes,"Cement and Concrete Research, vol. 11, no. 3, pp. 383-394, 1981.

[8] A. Carles-Gibergues, M. Cyr, M. Moisson, and E. Ringot, "A simple way to mitigate alkali-silica reaction," Materials and Structures/Materiaux et Constructions, vol.41, no. 1, p. 73-83, 2008.

[9] K. E. Hanna, G. Morcous, and M. K. Tadros, "Effectiveness of class c fly ash on mitigating alkalisilica reaction in concrete pavement," International Journal of Construction Education and Research, vol. 5, no. 3, pp. 167-181, 2009.

[10] F. Bektas, L. Turanli, T. Topal, and M. C. Goncuoglu, "Alkali reactivity of mortars containing chert and incorporating moderate-calcium fly ash," Cement and Concrete Research, vol. 34, pp. 2209-2214, 2004.

[11] D. S. Lane and C. Ozyildirim, "Preventive measures for alkali-silica reactions (binary and ternary systems)," Cement and Concrete Research, vol. 29, pp. 1281-1288, 1999.

[12] B. R. Hart, M. A. Powell, W. S. Fyfe, and B. Ratanasthien, "Geochemistry and mineralogy of fly-ash from the Mae Moh lignite deposit, Thailand," Energy Sources, vol.17 Issue 1, pp. 23-40,1995.

[13] P. Chindaprasirt, C. Jaturapitakkul, and T. Sinsiri, "Effect of fly ash fineness on compressive strength and pore size of blended cement paste, "Cement \& Concrete Composites, vol. 27, pp. 425-428, 2005

[14] S. Sujjavanich, K. Won-In, and D. Chayasuwan, "The problems of aggregate source and structural deterioration from alkali silica reaction in Thailand," in The first year report for Kasetsart University Research and Development Institute. Bangkok, Thailand: Kasetsart University, 2011.

[15] G. West, Alkali-aggregate reaction in concrete roads and bridges. Thomas Telford,1996.

[16] M. Richardson, "Minimising the risk of deleterious alkali-silica reaction in Irish concrete practice," Construction and Building Materials, vol. 19, pp. 654-660, 2005.

[17] ASTM C1260-01, Standard test method for potential alkali reactivity of aggregates mortar-bar method," ASTM, American Society for Testing and Materials, West Conshohocken, CD- ROM, pp. 5, 2003.

[18] ASTM C1567-04, "Standard Test Method for Determining the Potential Alkali-Silica Reactivity of Combinations of Cementitious Materials and Aggregate (Accelerated Mortar-Bar Method)," American Society for Testing and Materials, West Conshohocken, DOI: 10. 1520/ C1567-04, 2004.

[19] Innovation and Technology Division, "Report for PFA analysis," Innovation and Technology Division CPAC Co. Ltd., Thailand, 2010.

[20] K. Natesaiyer and K. C. Hover, "Insitu identification of ASR products in concrete," Cement and Concrete Research, vol. 18, pp. 455-463, May 1988.

[21] ASTM C856-04, "Standard Practice for Petrographic Examination of Hardened Concrete," American Society for Testing and Materials, West Conshohocken, 2004.

[22] L. J. Malvar and L. R. Lenke, "Efficiency of fly ash in mitigating alkali silica reaction based on chemical composition," ACI Materials Journal, vol. 103, no. 5, pp. 319-326, 2006. 
